\title{
A Study of Influence of Surface Nanosized \\ Gaseous Structures on the Water Freezing Rate and Wettability of Metallic and Oxide Substrates
}

\author{
Anton A. Karacharov* and Maxim N. Likhatski \\ Institute of Chemistry and Chemical Technology SB RAS \\ FRC "Krasnoyarsk Scientific Center SB RAS" \\ Krasnoyarsk, Russian Federation
}

Received 25.01.2020, received in revised form 10.02.2020, accepted 01.04.2020

Abstract. In a series of experiments using thermal gradient "cool water-warm substrate", an increase of number and sizes of surface gaseous nanostructures during an increase of the temperature difference was found to give rise to a decrease of surface hydrophobicity.

It was established that the higher the surface inhomogeneity, the shorter the time of water freezing. In case of HOPG, an extremely long lifetime of overcooled to $-20^{\circ} \mathrm{C}$ water of $\sim 100$ min was observed when surface gas nanostructures persisted. This can be understood in terms of a "gas screening" of surface inhomogeneity which could potentially act as ice nucleation centers.

Keywords: water freezing, icing, nanobubbles, potassium buthylxanthate, dibuthyldixanthogen, contact angle.

Citation: Karacharov A.A., Likhatski M.N. A study of influence of surface nanosized gaseous structures on the water freezing rate and wettability of metallic and oxide substrates, J. Sib. Fed. Univ. Chem., 2020, 13(2), 211-220. DOI: 10.17516/1998-28360176

(C) Siberian Federal University. All rights reserved

This work is licensed under a Creative Commons Attribution-NonCommercial 4.0 International License (CC BY-NC 4.0)

* Corresponding author E-mail address: karacharov@icct.ru 


\title{
Изучение влияния поверхностных наноразмерных \\ газовых структур на скорость замерзания воды \\ и смачиваемость металлических и оксидных субстратов
}

\author{
А.А. Карачаров, М.Н. Лихацкий \\ Институт химии и химической технологии СО РАН \\ ФИЦ «Красноярский научный центр СО РАН» \\ Российская Федераиия, Красноярск
}

Аннотация. В результатах экспериментов с каплей холодной воды и «теплой» подложкой (ВОПГ, нержавеющая сталь, $\mathrm{Ti}, \mathrm{TiO}_{2}, \mathrm{SiO}_{2}$ ) найдено, что увеличение числа и размера поверхностных газовых нанопузырьков при увеличении разности температур вода-подложка приводит к снижению гидрофобности поверхности.

Установлено, что чем выше шероховатость поверхности субстрата, тем меньше время замерзания воды на нем. На поверхности ВОПГ, при наличии на границе раздела т-ж заранее сгенерированных газовых нанопузырьков, наблюдалось длительное, до $\approx 100$ мин, существование капли переохлажденной жидкости, что можно объяснить тем, что более крупные газовые нанопузырьки экранируют поверхностные неоднородности ВОПГ, которые служат центрами нуклеации льда.

Ключевые слова: замерзание воды, обледенение, нанопузырьки, н-бутиксантогенат калия, дибутилдиксантоген, краевой угол смачивания.

Цитирование: Карачаров, А.А. Изучение влияния поверхностных наноразмерных газовых структур на скорость замерзания воды и смачиваемость металлических и оксидных субстратов / А.А. Карачаров, М.Н. Лихацкий // Журн. Сиб. федер. ун-та. Химия, 2020. 13(2). С. 211-220. DOI: 10.17516/1998-2836-0176

\section{Введение}

Образование льда на твердых поверхностях (обледенение) достаточно распространенное явление, которое может стать причиной серьезных проблем в различных технологических областях человеческой деятельности, включающих транспорт, электростанции, ветровые турбины и телекоммуникации [1]. Обледенение крыльев самолетов может повлечь существенный рост рисков отказа систем управления вплоть до крушения авиалайнера [2]. Кроме того, накопление льда и образование изморози может вызвать серьезные негативные последствия в работе рефрижераторов и систем кондиционирования [3].

К настоящему времени разработаны различные стратегии для борьбы с обледенением и удалением образовавшегося льда с поверхности, использующие либо электротермический или инфракрасный нагрев, либо нанесение специальных химических составов на основе спиртов или различных солей. Однако эти подходы зачастую высокоэнергозатратны и могут приводить к проблеме загрязнения окружающей среды $[4,5]$. Сейчас считается, что основная стратегия для борьбы с обледенением должна быть направлена на разработку и дизайн твердых поверх- 
ностей, обладающих льдорепеллентными свойствами и/или способностью подавлять нуклеацию и рост льда [6]. Более того, должна проводиться оптимизация как минимум сразу двух параметров: смачиваемости и шероховатости поверхности.

Так, в работах исследовательской группы под руководством Л.Б. Бойнович $[7,8]$ были проведены исследования функционирования супергидрофобных покрытий, полученных с применением наносекундного лазерного текстурирования как при положительных, так и при отрицательных температурах в различных средах. Очень перспективным выглядит комплекс методов, известный под аббревиатурой SLIPS, который предполагает импрегнирование пористой поверхности жидким лубрикантом, подбираемым для конкретной задачи, в том числе для текстурированных поверхностей, препятствующих льдообразованию [9]. Фактически создается «гладкая» межфазная граница жидкость (лубрикант) - жидкость (водная или иная фаза) с гораздо меньшей адгезией фаз, чем твердое-жидкость. Ограничения метода связаны прежде всего с тем, что лубрикант будет постепенно вымываться из пор; создать пористость поверхности не всегда просто или не всегда допустимо.

Одной из особенностей гидрофобных и супергидрофобных поверхностей является образование на них стабильных наноразмерных газовых структур (нанопузырьков), а также тонких газовых слоев $[10,11]$. Следовательно, выглядит перспективной идея формирования по аналогии с методом SLIPS границы раздела газ-жидкость (лед) за счет генерации поверхностных газовых структур. Недавно в ряде работ $[12,13]$ было показано образование поверхностных нанопузырьков при контакте холодной воды (около $0{ }^{\circ} \mathrm{C}$ ) и «теплых» подложек без добавления дополнительных реагентов. При этом увеличение разности температур между субстратом и водой приводит к росту числа и размера нанопузырьков на поверхности образца [13]. Ранее в наших исследованиях с помощью метода атомно-силовой микроскопии и спектроскопии (ACM/ACC) в воде было установлено, что обработка галенита $(\mathrm{PbS})$ и высокоориентированного пиролитического графита (ВОПГ) растворами н-бутилксантогената калия (KBuX) приводит к появлению на их поверхности наноразмерных газовых пузырьков [14]. В последующих работах $[15,16]$ методом АСC, в том числе с коллоидным зондом, было изучено влияние обработки микроэмульсией дибутилксантогената $\left(\mathrm{Bu}_{2} \mathrm{X}_{2}\right)$ на свойства ряда поверхностей и показано, что $\mathrm{Bu}_{2} \mathrm{X}_{2}$ проявляет свойства высокоактивного гидрофобизирующего реагента, вызывающего образование наноразмерных газовых структур на поверхности как гидрофобных, так и гидрофильных образцов [16].

Настоящая работа направлена на выявление роли поверхностных газовых структур (нанопузырьков) и действия ПАВ (водные растворы н-бутилксантогената калия и эмульсия дибутилдиксантогената) на скорость замерзания воды на поверхностях ряда субстратов: ВОПГа, титана, нержавеющей стали, рутила $\left(\alpha-\mathrm{TiO}_{2}\right)$ и $\mathrm{SiO}_{2}$. В задачи работы входило также изучение влияния поверхностных газовых структур, генерируемых методом температурного градиента, на величину краевого угла смачивания.

\section{Экспериментальная часть}

Реактивы. В работе использовали очищенный двукратной перекристаллизацией из ацетона промышленный н-бутилксантогенат калия (KBuX). Синтез водных эмульсий дибутил- 
диксантогената $\left(\mathrm{Bu}_{2} \mathrm{X}_{2}\right)$ проводили согласно методике, описанной в работе [15]. Все реактивы были не ниже класса ч.д.а.

Субстраты. В качестве субстратов в работе были использованы ВОПГ (НТ-МДТ, Москва), пластины кремния, покрытые слоем $\mathrm{SiO}_{2}$, и металлические пластины титана и нержавеющей стали (08X18H10T) размером 0,7х0,7 см. Методика полировки поверхности металлических пластин описана в работе [16]. Слой $\alpha-\mathrm{TiO}_{2}$ (рутила) получали путем электрохимического окисления шлифованной стороны Ті пластины в 0,5 моль/л растворе $\mathrm{H}_{2} \mathrm{SO}_{4}$ при 9 В в течение 30 мин согласно методике, описанной в [17].

Поверхность субстратов очищали от загрязнений перед каждым экспериментом, промывая последовательно гексаном, ацетоном, этиловым спиртом и деионизованной водой. Для модификации поверхности очищенные пластины погружали либо в 0,1 ммоль/л водный раствор $\mathrm{KBuX}$ на 10 мин, либо в эмульсию $\mathrm{Bu}_{2} \mathrm{X}_{2}$ на 1 мин, затем ополаскивали водой.

Измерения краевых углов смачивания. В экспериментах с разностью температур между каплей воды и подложкой как способом создания поверхностных газовых наноразмерных структур в качестве субстратов использовали металлические пластины Ті и нержавеющей стали, оксиды титана (рутил) и кремния, а также ВОПГ.

Измерение краевых углов смачивания проводили методом сидячей капли с помощью автоматизированного оптического анализатора ОСА 15EC, оснащенного температурным датчиком TPC-160 (DataPhysics, Германия) и элементом Пельтье. Объем капель деионизрованной воды во всех экспериментах был фиксирован и равен 10 мкл. Для поддержания температуры воды, равной $0,1^{\circ} \mathrm{C}$, игла дозирующего устройства была термостатирована при помощи криотермостата FT-211-25; расстояние между поверхностью образца и иглой составляло 30 мм. Температуру образцов задавали с помощью элемента Пельтье в диапазоне от 20 до $50{ }^{\circ} \mathrm{C}$ с шагом $10{ }^{\circ} \mathrm{C}$. Для выравнивания температур образцы выдерживали 30 мин на поверхности элемента Пельтье перед нанесением на них капли холодной воды. Для каждого образца проводили не менее пяти параллельных измерений.

\section{Измерения продолжительности замораживания воды на поверхности субстратов.} Изучение влияния состояния поверхности субстратов и заранее сгенерированных наноразмерных поверхностных газовых структур (нанопузырьков) на скорость нуклеации и кристаллизации льда было выполнено с помощью автоматизированного оптического анализатоpa OCA 15EC. Типичная методика эксперимента включала нанесение капли деионизованной воды объемом 10 мкл на поверхность субстрата; температуру образца задавали с помощью элемента Пельтье, выдерживая 15 мин при температуре $5{ }^{\circ} \mathrm{C}$ для выравнивания температур фаз. Затем начинали процесс охлаждения до минус $20^{\circ} \mathrm{C}$. Происходящие изменения записывали на встроенную видеокамеру в горизонтальной ориентации. За начало замораживания воды принят момент, когда капля становилась непрозрачной. Запись вели до полной заморозки капли. После достижения заданной температуры минус $20{ }^{\circ} \mathrm{C}$ начинали процесс разморозки, который также фиксировали на камеру. Для каждого типа субстратов проводили не менее пяти параллельных измерений.

Для выявления роли поверхностных газовых структур на скорость кристаллизации льда использовали метод разности температур (температура капли деионизованной воды $0,1{ }^{\circ} \mathrm{C}$, температура субстрата $50{ }^{\circ} \mathrm{C}$ ) для их генерирования перед проведением процесса заморозки 
капли. Заморозку начинали после достижения температуры образца $5{ }^{\circ} \mathrm{C}$. В качестве субстратов применяли $\mathrm{TiO}_{2}$ и ВОПГ.

\section{Результаты}

На рис. 1 приведены зависимости величины краевых углов смачивания (КУС) от температуры подложки (Ti, $\mathrm{Fe}, \mathrm{TiO}_{2}, \mathrm{SiO}_{2}$ и ВОПГ).

Как следует из данных рис. 1, при увеличении разности температур между каплей «холодной» $\left(0{ }^{\circ} \mathrm{C}\right)$ воды и «теплой» подложки наблюдается тенденция уменьшения величины (КУС) при росте температуры поверхности субстратов, однако, как правило, имеется одна выпадающая экстремальная точка (либо точка перегиба), которая для ВОПГ и пленки рутила представлена минимумом при $40{ }^{\circ} \mathrm{C}$, тогда как для $\mathrm{SiO}_{2}$ и нержавеющей стали и титана она соответствует локальному максимуму (рис. $1 a$ ).

Результаты экспериментов по изучению динамики замерзания капли деоинизованной воды при изменении температуры подложки от 5 до минус $20^{\circ} \mathrm{C}$ с варьированием природы (ВОПГ, нержавеющая сталь, $\mathrm{Ti}, \mathrm{TiO}_{2}, \mathrm{SiO}_{2}$ ) и вида обработки подложки (сорбция $\mathrm{KBuX}, \mathrm{Bu}_{2} \mathrm{X}_{2}$ ) приведены в табл. 1.

На рис. 2 в качестве примера приведены изображения, иллюстрирующие основные стадии замерзания капли воды на поверхности ВОПГ. За начало замерзания принят момент времени, когда капля становится мутной (рис. 2б). Затем происходит формирование в основании капли льда (рис. 26), граница которого начинает быстро распространятся вверх (рис. 22, д), и в конце происходит полная кристаллизация капли с образованием выпуклости на ее вершине (рис. $2 e$ ). Процесс таяния капли начинается с образования тонкого слоя жидкой воды между льдом и поверхностью субстрата, затем она распространяется вверх до полного плавления льда. Скорость таяния льда, как видно из данных табл. 1 , не зависит от сорбции ПАВ, а определяется преимущественно теплопроводностью материала субстрата.

Обработка раствором $\mathrm{KBuX}$ и эмульсией $\mathrm{Bu}_{2} \mathrm{X}_{2}$ увеличивает время замерзания, что демонстрирует ее несимбатное изменение с краевым углом смачивания. Наибольшее сокращение продолжительности замерзания капли воды наблюдается после контакта ВОПГ с раствором
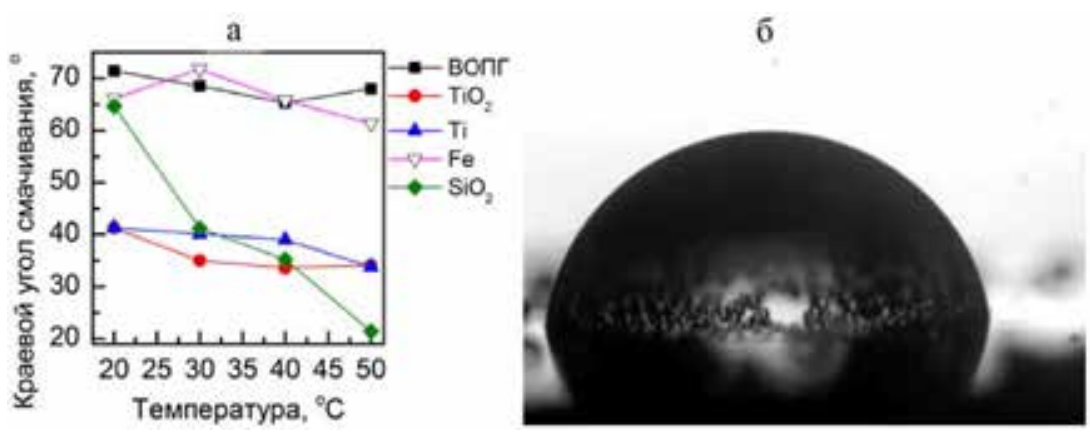

Рис. 1. Зависимость краевого угла смачивания от разности температур воды и субстрата (а); газовые макропузырьки, образовавшиеся при контакте капли холодной воды с температурой $0,1{ }^{\circ} \mathrm{C}$ и теплой поверхности ВОПГ $50^{\circ} \mathrm{C}$ (б)

Fig. 1. A Contact angle vs temperature "water-ubstrate" plot (a); gas nanobubbles arosen when cooled water at $0.1{ }^{\circ} \mathrm{C}$ was brought into contact with $\mathrm{HOPG}$ piece at $50{ }^{\circ} \mathrm{C}($ (б)

$$
-215-
$$


Таблица 1. Данные по времени замерзания воды $\left(\mathrm{T}_{\mathrm{f}}\right)$, плавления льда $\left(\mathrm{T}_{\mathrm{m}}\right)$, значения краевых углов смачивания $(\theta)$ и данные по теплопроводности $[18,19]$ и шероховатости поверхностей субстратов

Table 1. Time elapsed in processes of water freezing $\left(T_{f}\right)$, ice melting $\left(T_{m}\right)$, contact angles $(\theta)$, thermoconductivity and surface in homogeneity on different substrates

\begin{tabular}{|l|c|c|c|c|c|}
\hline \multicolumn{1}{|c|}{ Образец } & $\mathrm{T}_{\mathrm{f}}, \mathrm{c}$ & $\mathrm{T}_{\mathrm{m}}, \mathrm{c}$ & $\theta,{ }^{\circ}$ & $\begin{array}{c}\text { Теплопроводность, } \\
\text { Вт/м }{ }^{\circ} \mathrm{C}\end{array}$ & $\begin{array}{c}\text { Масштаб } \\
\text { неоднородности, нм }\end{array}$ \\
\hline ВОПГ исходный & 211,1 & 62,3 & 72,3 & $2,5(+) ; 229,3(\|)$ & $\begin{array}{c}\text { До 10 нм ступени, } \\
\text { атомарно гладкие террасы }\end{array}$ \\
\hline ВОПГ + $\mathrm{KBuX}$ & 119,1 & 40,8 & 77,9 & - & - \\
\hline $\mathrm{Fe}$ исходный & 116,5 & 49,3 & 69,4 & 16 & $30-40$ \\
\hline $\mathrm{Fe}+\mathrm{KBuX}$ & 108,8 & 86,75 & 71,7 & - & - \\
\hline $\mathrm{Fe}+\mathrm{Bu}_{2} \mathrm{X}_{2}$ & 106,4 & 42,8 & 71,3 & - & $30-40$ \\
\hline $\mathrm{Ti} \mathrm{исходный}$ & 109,6 & 61,9 & 55,2 & 22,3 & - \\
\hline $\mathrm{Ti}+\mathrm{KBuX}$ & 112 & 33 & 63,8 & - & - \\
\hline $\mathrm{Ti}^{\mathrm{Bu}} \mathrm{X}_{2}$ & 119 & 43 & 71,8 & - & $30-40$, есть и 170 \\
\hline $\mathrm{SiO}_{2}$ исходный & 128,2 & 40,2 & 60,4 & 1,35 & - \\
\hline $\mathrm{SiO}_{2}+\mathrm{KBuX}$ & 58,7 & 36,3 & 59,3 & - & - \\
\hline $\mathrm{SiO}_{2}+\mathrm{Bu}_{2} \mathrm{X}_{2}$ & 67,3 & 37,4 & 63,2 & - & $100-400$ \\
\hline $\mathrm{TiO}_{2}$ исходный & 76,5 & 68,9 & 67,0 & 13 & - \\
\hline $\mathrm{TiO}_{2}+\mathrm{KBuX}$ & 72,8 & 66,7 & 71,5 & - & - \\
\hline $\mathrm{TiO}_{2}+\mathrm{Bu}_{2} \mathrm{X}_{2}$ & 71,5 & 67,3 & 75,7 & - & \\
\hline
\end{tabular}

a

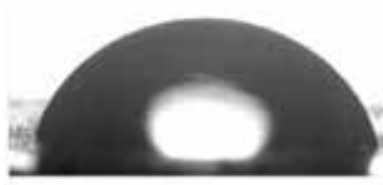

$\Gamma$

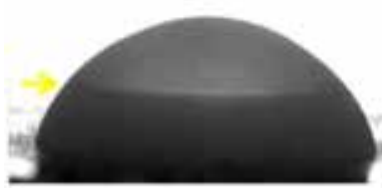

6

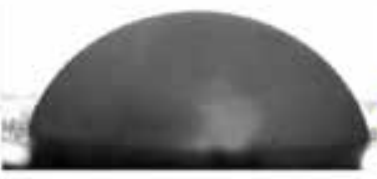

д

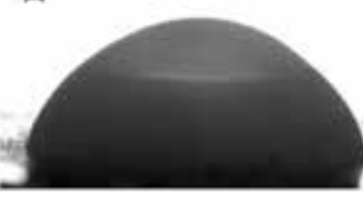

B

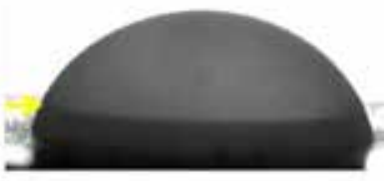

e

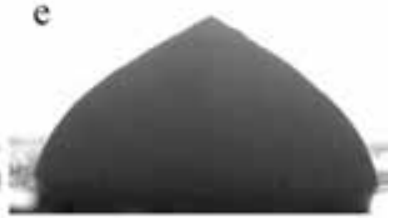

Рис. 2. Изображения, иллюстрирующие основные стадии замерзания капли деионизованной воды на поверхности ВОПГ при развертки температуры от 5 до минус $20^{\circ} \mathrm{C}: a$ - жидкая капля; $\sigma$ - тонкий слой льда в основании капли; в, г, $\partial$ - продвижение фронта льда снизу вверх капли; $e$ - полностью замерзшая капля. Стрелкой отмечена граница растущей фазы льда

Fig. 2. Images illustrating main water drop freezing stages during the sweep of temperature from $+5^{\circ} \mathrm{C}$ to $-20^{\circ} \mathrm{C}$ : (a) - liquid drop, (б) thin ice layer at the bottom of water drop, (в), (г), (д) - upward movement of the interphase boundary, (e) totally frozen drop. An arrow indicates the interphase boundary

$\mathrm{KBuX}$ - с 211 до 119 c, т.е. практически на 100 с. В наименьшей степени длительность замерзания капли воды уменьшается для оксидных субстратов $\left(\mathrm{TiO}_{2}, \mathrm{SiO}_{2}\right)$, поверхности которых в отличие от атомарногладкого ВОПГ имеют неоднородности порядка нескольких сот нанометров (табл. 1). 
Результаты экспериментов, когда на поверхности ВОПГ с помощью температурного градиента (температура подложки $50{ }^{\circ} \mathrm{C}$, капли воды около $0{ }^{\circ} \mathrm{C}$ ) генерировали нано- и макропузыри, показали, что в этих условиях происходило увеличение на два порядка времени замерзания капли воды (до минус $20{ }^{\circ} \mathrm{C}$ ), нанесенной на поверхность ВОПГ, что составляло $\approx 100$ мин. Между тем, на диоксиде титана применение данной методики не привело к заметному увеличению скорости замерзания.

\section{Обсуждение}

Как следует из полученных результатов, рост разности температур «подложка-вода», усиливающий генерацию воздушных газовых наностурктур на межафазной границе «твердое тело-жидкость», не приводит к усилению статической гидрофобности и нетривиально влияет на краевые углы смачивания (КУС) (см. рис. 1). Разумно предположить, что нетривиальное поведение КУСов в данной серии экспериментов определяется сложным взаимодействием таких разнонаправленно действующих факторов, как топография поверхности твердого тела, тип газовых наноструктур и поверхностная плотность покрытия ими твердого тела, увеличение вероятности коалесценции газовых наноструктур и подвижности трехфазной границы контакта с увеличением температуры и т.д. Так, в случае металлических подложек (Ti, нержавеющая сталь) начальный рост КУС может определяться увеличением плотности покрытия поверхности наноразмерными газовыми структурами, тогда как при превышении температуры, соответствующей экстремальной точке, наблюдаемое усиление статической гидрофильности, видимо, определяется увеличением скорости окисления металлов растворенным (и выделившемся в отдельную нанофазу) кислородом воздуха. Поверхности ВОПГ и $\mathrm{TiO}_{2}$, в гораздо меньшей степени подверженные окислению, демонстрируют присутствие минимума на температурной зависимости КУСов (рис. 1a), который, как мы полагаем, обусловлен, с одной стороны, ускорением достижения равновесного КУС с ростом температуры, с другой - генерацией при достаточно высоких температурах такого количества газовых наноструктур (рис. 1б), которое обеспечивает надежное закрепление трехфазной границы контакта.

Изучение продолжительности замерзания воды на поверхности ряда субстратов в зависимости от состояния их поверхности и наличия заранее сгенерированных поверхностных наноразмерных газовых структур на границе т-ж показали, что наибольшее время замерзания капли наблюдается для исходной атомарно гладкой (размер неоднородностей менее 10 нм) поверхности ВОПГ, содержащей очень мало центров для кристаллизации льда. Обработка же поверхности ВОПГ раствором КВuХ создает на ней неоднородности субмикронных масштабов, которые, выступая в роли центров гетерогенной нуклеации льда, сокращают время замерзания капли. Подобный же эффект сорбция $\mathrm{KBuX}$ и $\mathrm{Bu}_{2} \mathrm{X}_{2}$ оказывает на скорость замерзания капли воды на поверхностях других исследованных субстратов, хотя при этом сорбция КВuХ и $\mathrm{Bu}_{2} \mathrm{X}_{2}$ приводит к увеличению величины КУС. Согласно данным табл. 1, можно утверждать, что время замерзания капли воды будет определяться наличием на поверхности неоднородностей разной природы, выступающих в качестве центров кристаллизации льда.

Длительное существование капли переохлажденной жидкости на поверхности ВОПГ в случае заранее сгенерированных за счет изменения растворимости газов воздуха при нагреве 
воды поверхностных газовых структур на границе раздела т-ж может быть обеспечена в условиях, когда размеры поверхностных неоднородностей, которые могут выступать в качестве центров гетерогенной нуклеации льда, меньше по сравнению с размерами воздушных нано/ макропузырей. Не исключен также вклад химической составляющей поверхности: так, помимо больших масштабов топографической неоднородности диоксида титана, следует учитывать возможность преимущественной ориентации молекул воды вблизи поверхности подложки, в том числе за счет образования водородных связей Ті-Оㅜㄱ-ОН, что также энергетически должно облегчать нуклеацию льда.

\section{Заключение}

В экспериментах с каплей холодной воды, наносимой на «теплую» подложку (ВОПГ, нержавеющая сталь, $\mathrm{Ti}, \mathrm{TiO}_{2}, \mathrm{SiO}_{2}$ ), показано, что кривая зависимости значения КУС от температуры подложки имеет точку перегиба в районе $40{ }^{\circ} \mathrm{C}$ для всех изученных образцов. То есть увеличение числа и размера поверхностных газовых нанопузырьков при увеличении разности температур вода-подложка приводит к снижению гидрофобности.

Изучение длительности замерзания воды на поверхности субстратов в зависимости от сорбции $\mathrm{KBuX}$ и $\mathrm{Bu}_{2} \mathrm{X}_{2}$, наличия или отсутствия заранее сгенерированных газовых нанопузырьков показало, что чем выше шероховатость поверхности субстрата, тем меньше время замерзания воды на нем. Факторы, увеличивающие поверхностную неоднородность, например сорбция ПАВ, дополнительно сокращают время замерзания воды. Таким образом, длительность процесса замерзания воды на поверхности субстратов будет определяться в основном количеством и размером поверхностных неоднородностей, выступающих в качестве центров нуклеации и кристаллизации льда.

В экспериментах по замораживанию, при наличии на границе раздела фаз «вода-поверхность ВОПГ» заранее сгенерированных газовых нанопузырьков, наблюдалось длительное, до $\approx 100$ мин, существование капли переохлажденной жидкости. Этот эффект можно объяснить тем, что исходные поверхностные неоднородности ВОПГ, являющиеся центрами кристаллизации льда, экранируются более крупными газовыми нанопузырьками.

\section{Благодарности / Acknowledgements}

Исследование выполнено при финансовой поддержке Российского фонда фундаментальных исследований, в рамках научного проекта № 18-33-00302 мол_а: «Изучение влияния газовых нано- и микроразмерных структур на водо- и льдорепеллентные свойства поверхности».

Financial support for this work was provided by RFBR, project 18-33-00302 мол_а "A study of the effect of gaseous nano- and microstructures on the water and ice-repellent properties of the surface".

\section{Список литературы / References}

1. Carriveau R., Edrisy A., Cadieux P., Mailloux R. Ice Adhesion Issues in Renewable Energy Infrastructure. J. Adhes. Sci. Technol. 2012, Vol. 26 (4-5), P. 447-461.

2. Cao Y., Wu Z., Su Y., Xu Z. Aircraft Flight Characteristics in Icing Conditions. Prog. Aerosp. Sci. 2015, Vol. 74, P. 62-80. 
3. Shao L.L., Yang L., Zhang C.L. Comparison of Heat Pump Performance using Fin-andTube and Microchannel Heat Exchangers under Frost Conditions. Appl. Energy. 2010, Vol. 87(4), P. 1187-1197.

4. Makkonen L. Ice Adhesion Theory, Measurements and Countermeasures. J. Adhes. Sci. Technol. 2012, Vol. 26(4-5), P. 413-445.

5. Muhammad I.J., Alib A., Haq F., Zhang Q., Zhan X., Chen F. Icephobic Strategies and Materials with Superwettability: Design Principles and Mechanism. Langmuir. 2018, Vol. 34, P. $15425-15444$

6. Jung S., Dorrestijn M., Raps D., Das A., Megaridis C.M., Poulikakos D. Are Superhydrophobic Surfaces Best for Icephobicity? Langmuir. 2011, Vol. 27(6), P. 3059-3066.

7. Boinovich L.B., Emelyanenko A.M., Emelyanenko K.A., Maslakov K.I. Anti-icing properties of a superhydrophobic surface in a salt environment: an unexpected increase in freezing delay times for weak brine droplets. Phys. Chem. Chem. Phys. 2016, Vol. 18, P. 3131-3136.

8. Emelyanenko A.M., Domantovsky A.G., Emelyanenko K.A., Boinovich L.B. Synthesis of Wear-Resistant Superhydrophobic Coatings via Laser Micro- and Nanotexturing. Nanotechnologies in Russia, 2015, Vol. 10(7,8), P. 585-592.

9. Grinthal A., Aizenberg J. Mobile Interfaces: Liquids as a Perfect Structural Material for Multifunctional, Antifouling Surfaces. Chem. Mater. 2014, Vol. 26, P. 698-708.

10. Azadi M., Nguyen A.V., Yakubov G.E. Attractive Forces between Hydrophobic Solid Surfaces Measured by AFM on the First Approach in Salt Solutions and in the Presence of Dissolved Gases. Langmuir. 2015, Vol. 31(6), P. 1941-1949.

11. Tarábková H., Bastl Z., Janda P. Surface Rearrangement of Water-Immersed Hydrophobic Solids by Gaseous Nanobubbles. Langmuir. 2014, Vol. 30(48), P. 4522-14531.

12. Xua C., Penga S., Qiaoa G.G., Gutowskic V., Lohsed D., Zhang X. Nanobubble formation on a warmer substrate. Soft Matter. 2014, Vol. 10, P. 7857-7864.

13. An H., Tan B.H., Zeng Q., Ohl C.-D. Stability of Nanobubbles Formed at the Interface between Cold Water and Hot Highly Oriented Pyrolytic Graphite. Langmuir. 2016, Vol. 32(43), P. $11212-11220$.

14. Mikhlin Y.L., Karacharov A.A., Likhatskii M.N. Effect of Adsorption of Butyl Xanthate on Galena, PbS, and HOPG Surfaces as Studied by Atomic Force Microscopy and Spectroscopy and XPS, Int. J. Miner. Proc. 2015. Vol. 144, P. 81-89.

15. Karacharov A.A., Likhatskii M.N., Mikhlin Yu.L. Water Emulsions of Dibutyl Dixantogen and Their Interaction with the Surface of Highly Oriented Pyrolytic Graphite and Silicon Dioxide. Journal of Mining Science. 2016. Vol. 52(1), P. 184-189.

16. Karacharov A.A., Likhatski M.N. A comparative study of features of sorption of n-buthylxanthate and dibuthyldixanthogen onto metallic supports and rutile using in situ atomic force spectroscopy, J. Sib. Fed. Univ. Chem. 2019, Vol. 12(3), P. 336-346.

17. Koole R., Liljeroth P., Oosterhout S., Vanmaekelbergh D. Chemisorption Determines the Photovoltage of a Ti/TiO2/Au/Dye Internal Electron Emission Photovoltaic Cell. J. Phys. Chem. B. 2005. Vol. 109, P. 9205-9208.

18. Фиалков А.С., Бавер А.И., Сидоров Н.М., Чайкун М.И., Рабинович С.М. Пирографит. Получение, структура, свойства. Успехи химии. 1965. Вып. 1, С. 132-153. [Fialkov A.S., Baver A.I., 
Sidorov N.M., Tchaikun M.I., Rabinovich S.M. Pyrographite. Preparation, structure and properties. Uspekhi khimii. 1965. Issue. 1, P. 132-153. (In Russ.)]

19. Физические свойства горных пород и полезных ископаемых (петрофизика). Справочник геофизика. Под ред. Дортман Н.Б. М.: Недра, 1984. 455 с. [Physical properties of rocks and minerals (petrophysics). Handbook of Geophysics Under Ed. Dortman N.B. Moscow: Nedra, 1984. 455 p. (In Russ.)] 